\title{
Alteration in morpho-physiological attributes of Leymus chinensis (Trin.) Tzvelev by exogenous application of brassinolide under varying levels of drought stress
}

\author{
Jun Lv ${ }^{1}$, Xue-feng Zong ${ }^{1}$, Anjum Shakeel Ahmad ${ }^{1,2}$, Xiao Wu ${ }^{1}$, Chao Wu ${ }^{1}$, Yun-peng Li ${ }^{1}$, \\ and San-gen Wang ${ }^{1^{*}}$
}

'Southwest University, College of Agronomy and Biotechnology, Chongqing 400716, China.

"Corresponding author (wangsg@swu.edu.cn).

${ }^{2}$ University of Agriculture, Department of Agronomy, Faisalabad 38040, Pakistan.

Received: 14 July 2019; Accepted: 3 November 2019; doi:10.4067/S0718-58392020000100061

\begin{abstract}
Climate change and prolong drought adversely affect the grassland ecosystem, is precarious environmental constraint restricting plant growth and productivity. An experiment was conducted to alleviate adverse impacts of drought on physiochemical and morphological attributes of Leymus chinensis (Trin.) Tzvelev using brassinosteroid (BR). Treatments comprised well watered control (soil water contents 80\%-85\%) including Control (T0) and Control+ BR (TB0), moderate drought stress (soil water contents 50\%-55\%) including (T1) and T1+ BR (TB1) and severe drought stress (soil water contents 30\%-35\%) including (T2) and T2+ BR (TB2), they were laid out in completely randomized design with five replicates. Drought stress significantly impaired growth, osmotic substances, photosynthetic rate, and other physiochemical process. Moreover, perturbation in recorded attributes was aggravated by increasing drought severity from moderate to severe. Nevertheless, BR application $\left(0.1 \mathrm{mg} \mathrm{L}^{-1}\right)$ improved plant weight (38.8\%-46.2\%), relative water content (23.4\%-29.1\%), chlorophyll $a$ (16.6\%-56.5\%), chlorophyll $b$ (8.5\%-16.9\%), carotenoids (29.1\%-67.3\%), soluble sugars (1.7\%-29.4\%), free amino acids (15.4\%-19.4\%), and proline content (45.2\%-79.4\%); while, lowered malondialdehyde (34.8\%-45.4\%) at each level of drought. Likewise, BR application enhanced net photosynthetic rate (69.8\%-165.1\%), transpiration rate (45.0\%-146.9\%), water utilization efficiency (9.3\%-16.0\%), carboxylation utilization efficiency (80\%$250 \%)$, sunlight utilization efficiency (66.6\%-158.8\%) and improved chlorophyll fluorescence characteristics at each level of drought, as compared to untreated controls. The adverse implications on physiochemical and morphological attributes were aggravated with the enhancing severity of drought from control to severe drought. Yet, $0.1 \mathrm{mg} \mathrm{L}^{-1}$ exogenous BR improved morphological and physiochemical attributes remarkably over respective controls and hence can be used to improve growth of drought stressed L. chinensis.
\end{abstract}

Key words: Brassinolide (BR), drought stress, Leymus chinensis, osmotic adjustment, photosynthetic performance.

\section{INTRODUCTION}

Sheep grass, Leymus chinensis (Trin.) Tzvelev is a perennial and rhizomatous grass. High carbohydrates, protein contents, and good palatability enhance its forage value and thus makes it an important species of Chinese grassland (Liu et al., 2016). It thrives under diverse environmental conditions ranging from southern Chinese loess plateau to the northern Russian Baikal and from Sanjiang plain of eastern China. Moreover, it also extends to the Ulan Bator in 
Mongolia, covering almost $41 \%$ of China's total land mass. However, the productivity of the grasslands is diminishing continually owing to climate change, imbalanced nutrient management, rigorous grazing, and abiotic stresses. Among the abiotic stresses, recurrent incidence of drought hampers innumerable metabolic and physiochemical attributes of crops. Additionally, drought deleteriously impacts plant growth, productivity, and biomass accumulation under erratic rainfall intensities, frequency, and pattern.

Drought mediated perturbations that affect biomass accumulation of $L$. chinensis are aggravated oxidative stress, lipid peroxidation of bio-membranes, decreased biosynthesis of chlorophyll, stomatal conductance, fluorescence, and solar radiation use efficiency. Consequently, biomass accumulation and growth is adversely affected and thus sustainability of grassland is highly dubious (Liu et al., 2015). Drought stress exerts its devastating effects on plant growth by the disruption of processes such as cell division, extension, and differentiation, which ultimately alters the physio-morphological and genetic events as well as their complex interactions (Farooq et al., 2009; Gao et al., 2018). Reactive oxygen species (ROS) often overpower the biosynthesis of antioxidant enzymes. Consequently, lipid peroxidation aggravates and reduces plant capability to maintain its water potential and turgor (Anjum et al., 2012), while enzymes involved in biosynthesis of chlorophyll downregulate and reduces photosynthetic capacity of plant. Likewise, drought impairs the capability of plant to fix $\mathrm{CO}_{2}$ in photosynthesis, net photosynthetic rate, and eventually biomass accumulation (Anjum et al., 2011). Moreover, drought-induced oxidative stress reduces electron flow in electron transport chain, disintegrate oxygen evolving complex at photosystem-II, and depress quantum yield of light reaction. Consequences of these metabolic adversities are aggravated by photoinhibition and lipid peroxidation (Huang et al., 2013).

Adversities of drought can be alleviated through numerous strategies such as adjusting of sowing seasons, growing of tolerant genotypes, application of mulching to reduce soil moisture loss, and exogenous application of osmo-protectants, nutrients, and growth substances. Although, other tactics also prove effective to alleviate adverse impacts of drought, foliar growth regulators application on plants has proved to be an economically feasible strategy to alleviate adverse drought effects. Exogenously applied plant growth regulators improve the plant capability to make osmotic adjustments, strengthen antioxidant enzyme defense mechanism, upregulate the biosynthesis of chlorophyll, improve radiation use efficiency, and ultimately enhance growth and biomass accumulation. Furthermore, plant growth regulators mediated accumulation of osmo-protectants help the plant to maintain the cellular water potential by depressing osmotic potential. Increased activities of antioxidant enzymes escalate the detoxification of ROS and therefore lessen the lipid peroxidation (Zong et al., 2018). Maintenance of permeability of biological membranes and water potential are of prime importance for plant cells to exhibit growth (Anjum et al., 2012), whereas higher water potential activates hydrolases and thus lessens apoplast for cell expansion under growth. Regulation and biosynthesis of antioxidant enzymes enhance photosynthesis and biomass accumulation of plants under stressed environment (Sapeta et al., 2013). Improvements in activities of antioxidant enzymes accelerate the detoxification of hydroxyl radical $\left(\mathrm{OH}^{*}\right)$, superoxide radical $\left(\mathrm{O}_{2}{ }^{*}\right)$ and singlet oxygen $\left({ }^{(} \mathrm{O}_{2}{ }^{*}\right)$ to their respective detoxified forms. Furthermore, stress tolerant plants enhance the activity of antioxidant enzymes such as catalase (CAT), peroxidase (POD), and superoxide dismutase (SOD) that scavenge the ROS to safeguard the cellular organelles and ensure their normal functioning under stressed conditions (Huang et al., 2015). Plant growth regulating substances modulate growth by regulating physiological processes taking place within the plant body and induct amelioration of damaging effects of abiotic stresses (Anjum et al., 2011; 2013).

Brassinosteroids (BRs) are one of the novel classes of plant hormones that are polyhydroxysteroids in nature and are essentially involved in plant growth and development (Jin-huan et al., 2015). Many physiological functions have been known to be governed by BR such as cellular division and differentiation, stomatal oscillations, photosynthesis, and respiration (Vriet et al., 2012). BRs have been known to play protective roles in plants against numerous stresses (Divi et al., 2010). Furthermore, under stressed conditions BR application substantially improves plant growth by modulating the accumulation of osmo-protectants and antioxidant activity, lowering the ROS production, lipid peroxidation, enhancing radiation use efficiency, and chlorophyll fluorescence. Ultimately, photosynthetic activity improves owing to BR mediated improvements in innumerable metabolic and physiochemical attributes. Besides, these physiochemical attributes often depict strong correlation with morphological attributes as well and therefore improves biomass accumulation (Liu et al., 2015). Conclusively, drought induces numerous perturbations in plant metabolism at the subcellular level which ultimately change the phenotypic expression of morphological attributes. 
Foliar applied BR might effectively alleviate adverse impacts of drought in L. chinensis and improve biomass accumulation under stressed environments. It was hypothesized tolerant plants would have a higher growth rate, would be associated with more chlorophyll, and other physiological and biochemical attributes. Hence experiment was conducted to alleviate adverse impacts of drought on L. chinensis through exogenously applied BR under varying severity of moisture deficit and studying the dynamics of physiochemical attributes as potential modulators of growth and biomass accumulation of drought stressed L. chinensis.

\section{MATERIALS AND METHODS}

\section{Experimental details}

A pot study was conducted to estimate the consequence of brassinosteroids (BR) treatment on growth and physiological attributes of Leymus chinensis (Trin.) Tzvelev plants under varying levels of drought stress, in rainproof shed at Southwest University ( $106^{\circ} 26^{\prime} 02^{\prime \prime}$ E, $29^{\circ} 49^{\prime} 32^{\prime \prime} \mathrm{N} ; 220 \mathrm{~m}$ a.s.l.) in 2015 . There was light with about 1200 yearly sunshine hours. The average photosynthetically active radiation (PAR) was $1150 \mu \mathrm{mol} \mathrm{m}^{-2} \mathrm{~s}^{-1}$ for the experimental time and average temperature is $25^{\circ} \mathrm{C}$. Leymus chinensis seeds were collected from Ecosystem Research Station, Academy of Sciences, Inner Mongolia, China. Seeds were dried at room temperature, poured into bags, and stored in refrigerator at $4{ }^{\circ} \mathrm{C}$. Seeds were spread in petri dishes lined with filter papers for germination and placed in an incubator $\left(25 \pm 1{ }^{\circ} \mathrm{C}\right.$ incubation, 14:10 h day/night illumination time and $2500 \mathrm{~lx}$ light intensity). At first a preparatory experiment was conducted to evaluate whether exogenously applied BR at various concentrations $\left(0,0.01,0.1\right.$, and $\left.1.0 \mathrm{mg} \mathrm{L}^{-1}\right)$ could promote $L$. chinensis growth under well-watered control condition. In ethanol, BR (Sigma-Aldrich St. Louis, Missouri, USA) was dissolved then dilute with purified water to different concentrations. The best effective dose in improving growth and other attributes for plants was $0.1 \mathrm{mg} \mathrm{L}^{-1} \mathrm{BR}$ spray.

Then transplanting of L. chinensis seedlings (30) were done $1 \mathrm{wk}$ after germination into pots having diameter of 34 $\mathrm{cm}$ and height of $24 \mathrm{~cm}$. The pots were filled with sandy loam soil having $\mathrm{pH}$ 6.4. Total $\mathrm{N}$ in the soil sample was 3.83 $\mathrm{g} \mathrm{kg}^{-1}, 3.78 \mathrm{~g} \mathrm{~kg}^{-1}$ total $\mathrm{P}$ and $10.24 \mathrm{~g} \mathrm{~kg}^{-1}$ was total $\mathrm{K}, 1007.43 \mathrm{mg} \mathrm{kg}^{-1}$ available $\mathrm{N}, 9.29 \mathrm{mg} \mathrm{kg}^{-1}$ available $\mathrm{P}, 132.5 \mathrm{mg} \mathrm{kg}^{-1}$ available $\mathrm{K}$ and $143.65 \mathrm{~g} \mathrm{~kg}^{-1}$ was organic matter. The same management practices were carried out after transplantation of seedlings. Seedlings were supplied with Hoagland's nutrient solution every $5 \mathrm{~d}$ to ensure suitable nutrient supply. When the L. chinensis plants attained a height of $18-20 \mathrm{~cm}$, thinning was done to keep 25 plants per pot.

The experiment consisted of three different levels of soil water contents, control (well-watered), drought (mild) and severe drought. Soil water contents were evaluated everyday by probes (IMKO Micromodultechnik GmbH, Ettlingen, Germany). The BR was sprayed on leaves of L. chinensis at the rate of $0.1 \mathrm{mg} \mathrm{L}^{-1}$ concentration and in control water (distilled) was sprayed. All three sprays of BR were applied every $5 \mathrm{~d}$. To avoid the effect of sunlight and temperature on BR effect, spraying time was in the evening. The plants were covered with different concentrations of BR or water droplets but not dripping appropriate. In all, there were six treatments with five replicates. So the six treatments were well watered control (soil water contents 80\%-85\%) including Control (T0) and Control+ BR (TB0), moderate drought stress (soil water contents 50\%-55\%) including (T1) and T1+ BR (TB1) and severe drought stress (soil water contents $30 \%-35 \%$ ) including (T2) and T2+ BR (TB2).

Plants were sampled 7,14 , and $21 \mathrm{~d}$ after the application of treatments to assess growth, physiological, and biochemical attributes.

\section{Growth attributes}

Plants were uprooted (from pots) and firstly rinsed using tap fresh water and then washed (2-3 times) with double distilled water. Adhered water was absorbed using filter paper and then fresh weight was determined. Oven at $105^{\circ} \mathrm{C}$ for 15 min was used to dry the samples, and then at $65^{\circ} \mathrm{C}$ until constant weight to measure dry weight (about $48 \mathrm{~h}$ ).

\section{Physiological and biochemical attributes}

Leaf relative water content was calculated using the method of Liu et al. (2015). The malondialdehyde (MDA) content was determined by thiobarbituric acid (TBA) method (Jin-huan et al., 2015). Trichloroacetic acid (5\%) $5 \mathrm{~mL}$ was used to homogenize the sample. After centrifugation of the homogenate supernatant TBA was added, then the mixture was 
heated at $98{ }^{\circ} \mathrm{C}$ for $10 \mathrm{~min}$ and cooled. After centrifugation, the absorbance was measured at $532 \mathrm{~nm}$. Leaf electrical conductance (EC) was measured by adopting Jin-huan et al. (2015) method. Soluble sugars content was assayed by anthronecolorimetric method (Zong et al., 2018). The material was put into a centrifuge tube, where $80 \%$ ethanol was added. The mixture was incubated at $80^{\circ} \mathrm{C}$ in a shaking water bath for $30 \mathrm{~min}$, and then centrifuged at $5000 \mathrm{rpm}$ for $5 \mathrm{~min}$. The pellets were re-extracted twice with $80 \%$ ethanol. Extracted soluble sugars were determined spectrophotometrically using the anthrone method at $625 \mathrm{~nm}$. Coomassie brilliant blue method was used to find the soluble protein content (Liu et al., 2015). Free amino acids were assessed by using ninhydrin colorimetric method of Huang et al. (2010). Proline content was ascertained by using the ninhydrin method (Jin-huan et al., 2015).

Photosynthetic pigments were assessed by using the technique of spectrophotometry (Liu et al., 2015). Leaf sample $(0.1 \mathrm{~g})$ was placed in $15 \mathrm{~mL}$ centrifuge tube after grinding along with miscible liquids $(10 \mathrm{~mL})$ by $95.5 \%$ acetone and absolute ethyl alcohol in 1:1 ratio. Black plastic bags were used to cover the samples. Samples were kept in dark place until the sample changed into white. The absorbance of spectrophotometer was measured at 665, 649, 470 and $652 \mathrm{~nm}$, respectively.

Plant photosynthetic characteristics were measured using a portable light synthetic measuring (Li-6400; LI-COR, Lincoln, Nebraska, USA) in optical photosynthetically active radiation (PAR) 1000 ( $\mu \mathrm{mol}$ [photon] $\mathrm{m}^{-2} \mathrm{~s}^{-1}$ ) under different treatments. Indexes included net photosynthetic rate $\left(\mathrm{P}_{\mathrm{N}}\right)$, stomatal conductance $\left(\mathrm{g}_{\mathrm{s}}\right)$, intercellular $\mathrm{CO}_{2}$ concentration $\left(\mathrm{C}_{\mathrm{i}}\right)$, sunlight utilization efficiency (SUE), transpiration rate (E), carboxylation utilization efficiency (CUE), water use efficiency (WUE) and stomatal limitation $\left(\mathrm{L}_{\mathrm{s}}\right)$. Each index was calculated using average of five values.

Open gas exchange system (LI-6400) with an integrated fluorescence chamber (LI-6400-40 leaf chamber fluorometer; LI-COR) was used to determine the chlorophyll fluorescence parameters. Randomly selected five plants and their leaves were kept in dark for $20 \mathrm{~min}$, and then kept in weak light $\left(0.1 \mu \mathrm{mol} \mathrm{m} \mathrm{m}^{-2}\right)$. The minimal fluorescence yield of the darkadapted state $\left(F_{0}\right)$ was measured, and then saturation pulse light $\left(3000 \mu \mathrm{mol} \mathrm{m}^{-2} \mathrm{~s}^{-1}\right) 0.8 \mathrm{~s}$ was passed to determine the maximal fluorescence yield of the dark-adapted state $\left(\mathrm{F}_{\mathrm{m}}\right)$. The steady-state fluorescence $\left(\mathrm{F}_{\mathrm{s}}\right)$ was measured after $30 \mathrm{~min}$ light adaptation and the maximal fluorescence yield of the light-adapted state $\left(\mathrm{F}_{\mathrm{m}}{ }^{\prime}\right)$ was measured by $0.8 \mathrm{~s}$ saturation pulse light $\left(3000 \mu \mathrm{mol} \mathrm{m} \mathrm{s}^{-1}\right)$. Optimal/minimal quantum yield of photosystem (PSII) was calculated as: $\mathrm{F}_{\mathrm{v}} / \mathrm{F}_{0}=\left(\mathrm{F}_{\mathrm{m}}-\mathrm{F}_{0}\right) / \mathrm{F}_{0}$, optimal/maximal quantum yield of PSII or photochemical efficiency of PSII was calculated as: $F_{v} / F_{m}=\left(F_{m}-F_{0}\right) / F_{m}$, and photosynthetic quantum yield of PSII was calculated as: $\Phi$ PSII $=\left(\mathrm{F}_{\mathrm{m}}{ }^{\prime}-\mathrm{F}_{\mathrm{s}}\right) / \mathrm{F}_{\mathrm{m}}$ '.

\section{Statistical analysis}

Data were analyzed using Excel 2007 and SPSS statistical software (SPSS Inc., Chicago, Illinois, USA) for analysis of variance ANOVA and DPS19.0 software (Windows, Chicago, USA) was used for Duncan's multiple range test to compare the treatments' means.

\section{RESULTS}

\section{Growth and development}

Growth and development of L. chinensis declined significantly under drought stress. Decline in growth and development aggravated with the enhancement of severity of drought. Hence, increase in severity of stress from moderate to severe, drought caused 58.9\%-59.6\% reduction in plant fresh weight and 22.2\%-32.3\% diminishment in relative water content of L. chinensis. Conversely, BR spray ameliorated all the growth attributes of L. chinensis. At moderate stress control, the BR application improved the fresh weight and relative water contents by $46.2 \%$ and $23.4 \%$, respectively, at 14 DAT, after which a decline in growth and development was evident. Comparatively more increment in fresh weight (38.8\%) and relative water content (29.1\%) over control were recorded at 14 DAT at severe drought stress (Figure 1).

\section{Lipid peroxidation}

A significant increase in MDA and electrical conductivity (EC) of L. chinensis was recorded under stressed environment over the control. Furthermore, accumulation of MDA was aggravated with increase in severity of drought stress from moderate to severe. MDA biosynthesis increased by $109.3 \%$ under moderate and $184.4 \%$ under severe drought. EC was enhanced continually from 7 to 21 DAT, depending upon the stress severity. However, application of BR lowered the 
Figure 1. Effect of foliar application of brassinosteroid (BR) on fresh weight, dry weight, relative water content, and plant height of Leymus chinensis under varying levels of drought stress.
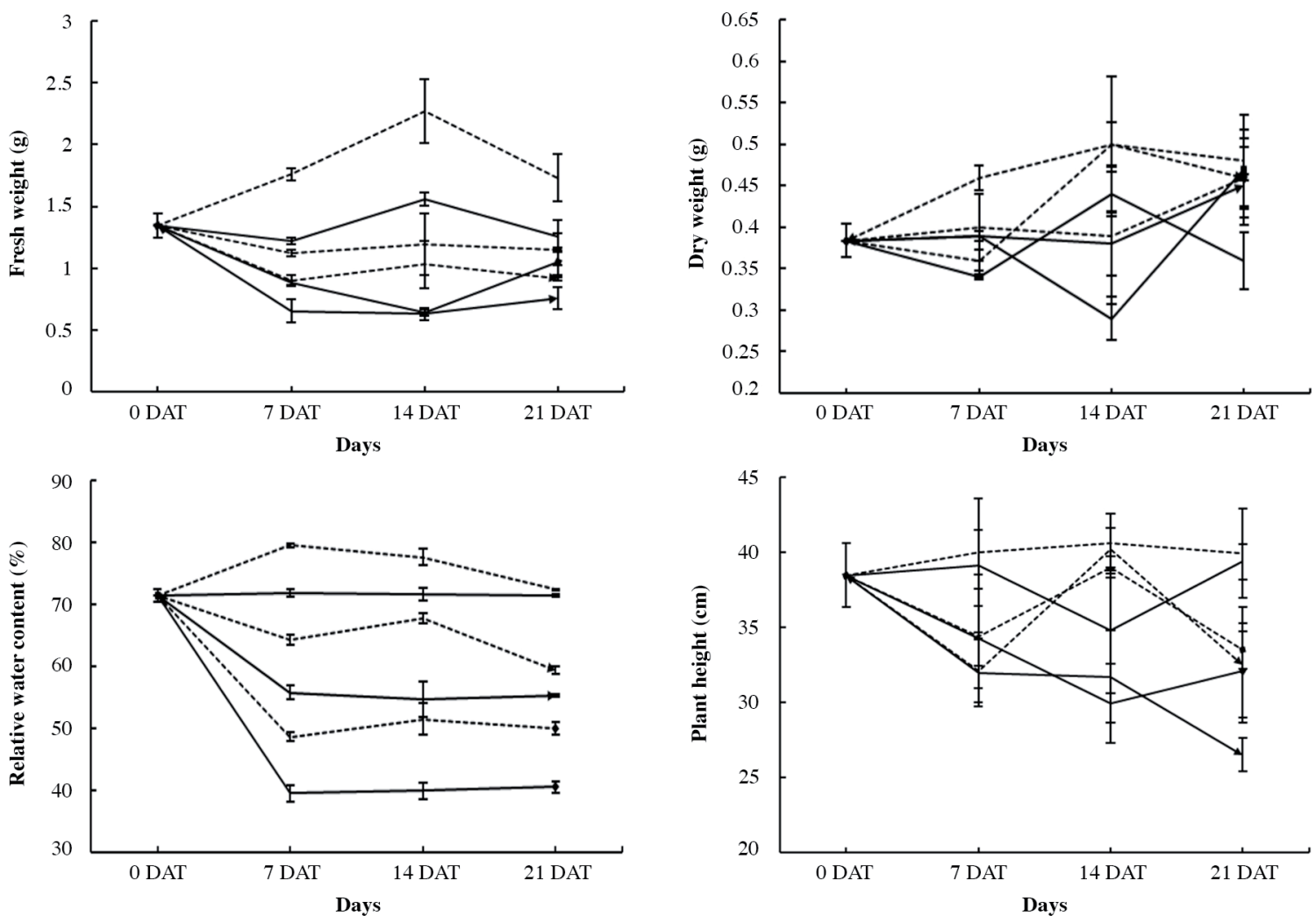

Mean value $\pm \mathrm{SE}(n=5)$. DAT: Days after treatments; T0: control; TB0: control + BR; T1: moderate drought stress; TB1: moderate drought stress + BR; T2: severe drought stress; TB2: severe drought stress+ BR.

accumulation of MDA and decreased EC at all levels of drought stress. At both moderate and severe drought, highest decrease in MDA content (45.4\% and 34.8\%, respectively) and EC (27.6\% and $26.1 \%$, respectively) was recorded in response to BR application at 14 DAT, when compared with untreated control (Figure 2).

Figure 2. Effect of foliar application of brassinosteroid (BR) on malondialdehyde (MDA) and leaf electrical conductance (EC) of Leymus chinensis under varying levels of drought stress.
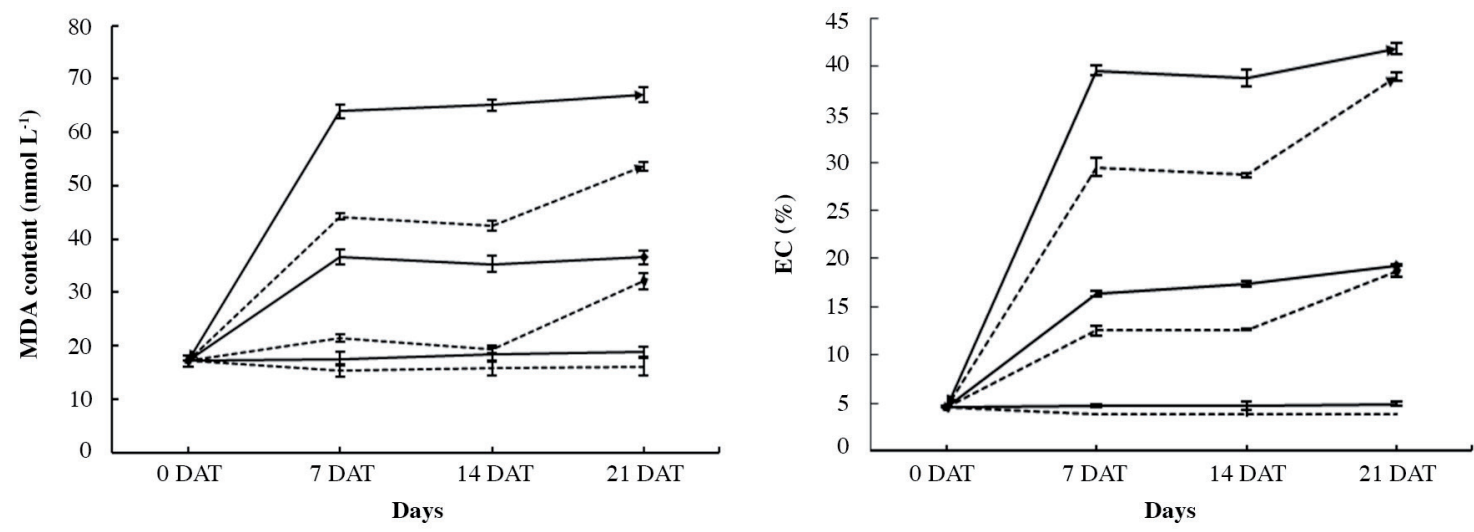

Mean value $\pm \mathrm{SE}(n=5)$. DAT: Days after treatments; T0: control; TB0: control + BR; T1: moderate drought stress; TB1: moderate drought stress + BR; T2: severe drought stress; TB2: severe drought stress+ BR. 


\section{Osmo-protectants}

A significant increase in accumulation of organic osmo-protectants in L.chinensis plants under drought stress was observed and their concentration increased with severity of stress. Osmo-protectants accumulation increased linearly from 7 to 21 DAT whereby their maximum concentrations were noticed. Furthermore, their concentrations increased with enhancing severity of from moderate to severe. Hence, an increment of 79.2\%-122.5\%, 112.0\%-227.9\%, and $1523.0 \%-4916.5 \%$ in soluble sugars, free amino acids, and proline was recorded over control. Nonetheless, application of BR to L. chinensis plants upregulated the accumulation of osmo-protectants. Comparatively more accumulation of osmo-protectants was evident 14 DAT. Thus, foliar BR mediated improvements in accumulation of free amino acids, soluble sugars and proline contents was $29.4 \%, 19.4 \%$, and $79.4 \%$ under moderate drought and $1.7 \%, 15.4 \%$ and $45.2 \%$ under severe drought over control was recorded (Figure 3).

Figure 3. Effect of foliar application of brassinosteroid (BR) on soluble sugars, soluble proteins, free amino acids and free proline contents of Leymus chinensis under varying levels of drought stress.
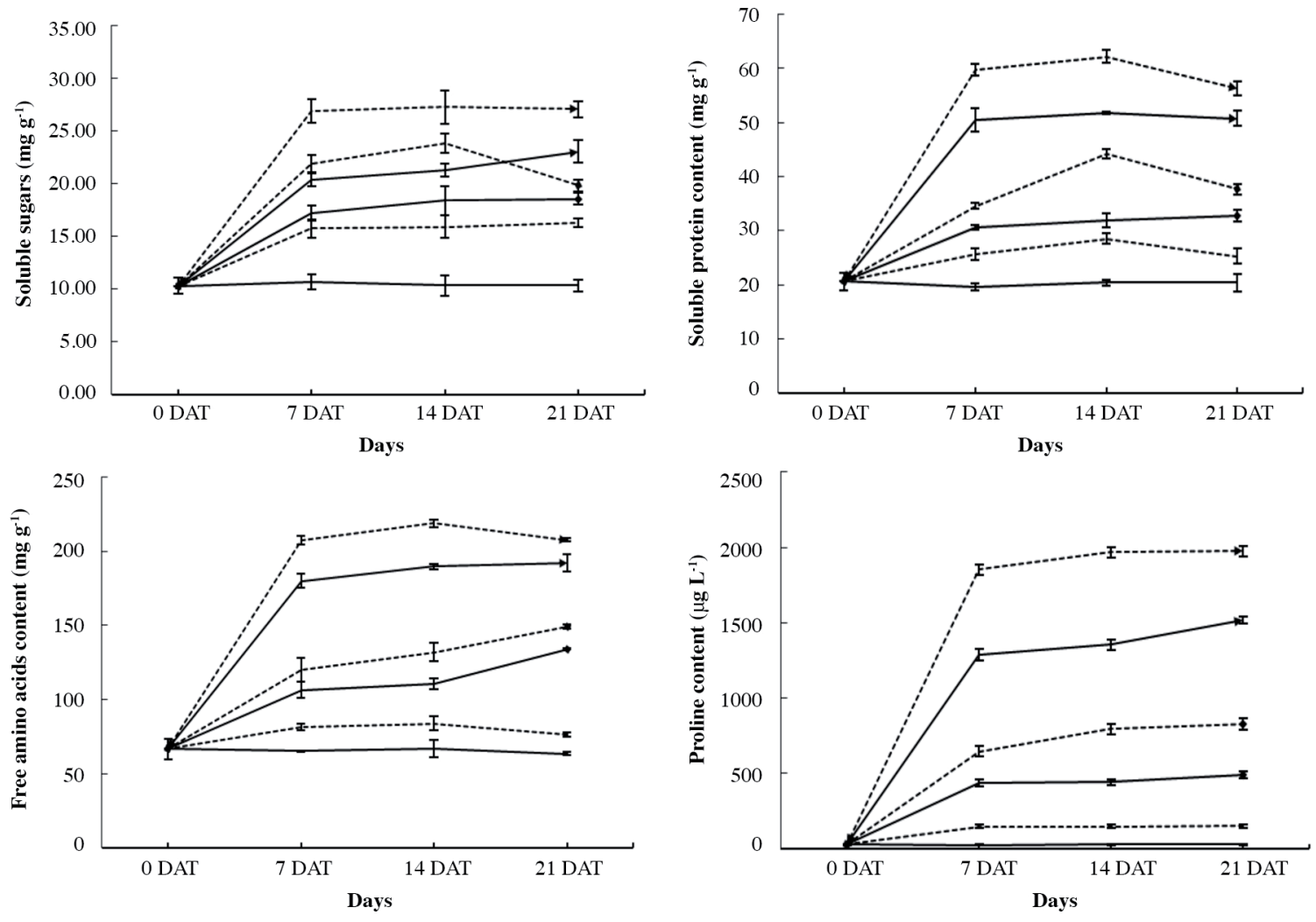

Mean value $\pm \mathrm{SE}(\mathrm{n}=5)$. DAT: Days after treatments; T0: control; TB0: control + BR; T1: moderate drought stress; TB1: moderate drought stress + BR; T2: severe drought stress; TB2: severe drought stress+ BR.

\section{Photosynthetic pigments}

Significant downregulation in biosynthesis of photosynthetic pigments was exhibited by L. chinensis under drought. A diminishing trend in biosynthesis of photosynthetic pigments was observed with aggravating severity of drought. Relatively higher decrease in biosynthesis of Chla (9.0\%-40.1\%) and Chlb (9.0\%-40.1\%) over control was observed at 7 DAT. Comparatively more reduction in carotenoids biosynthesis $(32.7 \%-104.2 \%)$ and Chla/b ratio (8.0\%-14.3\%) over control were recorded at 21 DAT. BR spray effectively alleviated the damaging effect of drought on photosynthetic pigments. Thus, under moderate drought comparatively more improvements in biosynthesis of Chl $a, \mathrm{Chl} b$, and Chla/b was recorded 7 DAT and carotenoids 21 DAT under BR spray over control. Hence, BR triggered improvements in Chl $a$, $\mathrm{Chl} b$ and Chla $a$ ratio were $16.6 \%, 8.5 \%$, and $6.7 \%$, respectively, under moderate stress over control 7 DAT. Conversely, a boost of $29.1 \%$ in carotenoid biosynthesis under BR over control was observed at 21 DAT under moderate stress 
conditions. Under severe stress, the trend was different since maximum increase in Chla (56.5\%) occurred at 7 DAT; $\mathrm{Chl} b(16.9 \%)$ and carotenoids (67.3\%) at $21 \mathrm{DAT}$; and Chla/b ratio (8.4\%) was highest at 14 DAT over control (Figure 4).

\section{Gas exchange attributes}

Drought stress significantly altered gas exchange characteristics of L. chinensis. Furthermore, adverse effects of drought worsened with increasing stress severity. Thus, a decrease in $\mathrm{P}_{\mathrm{N}}(42.1 \%-88.8 \%)$, E (60.6\%-91.0\%), CUE (45.7\%$91.3 \%), \mathrm{L}_{\mathrm{s}}(30.9 \%-86.1 \%)$, and SUE (42.6\%-88.5\%), depending upon severity of drought, was observed under stress. $\mathrm{C}_{\mathrm{i}}$ and WUE were increased by $7.5 \%-27.5 \%, 6.3 \%-36.2 \%$, respectively, depending upon the stress severity. However, a strange behavior was observed regarding $\mathrm{g}_{\mathrm{s}}$, which was decreased at moderate stress (56.3\%) while increased at severe stress (4.2\%). However, BR application exerted ameliorative role on gas exchange attributes. At moderate stress, BR spray enhanced the $\mathrm{P}_{\mathrm{N}}(69.8 \%), \mathrm{g}_{\mathrm{s}}(42.9 \%)$, E (45.0\%), WUE (16.0\%), CUE (80\%), $\mathrm{L}_{\mathrm{s}}(55.2 \%)$, and SUE (66.6\%) while $\mathrm{C}_{\mathrm{i}}(8.6 \%)$ was decreased. While, at severe drought, increase in $\mathrm{P}_{\mathrm{N}}(165.1 \%)$, E (146.9\%), WUE (9.3\%), CUE (250.0\%), $\mathrm{L}_{\mathrm{s}}(600.0 \%)$, and SUE $(158.8 \%)$, and decrease in $\mathrm{g}_{\mathrm{s}}(72.0 \%)$ and $\mathrm{C}_{\mathrm{i}}(21.1 \%)$ was caused by application of BR, over untreated control (Table 1).

\section{Chlorophyll fluorescence}

A significant reduction in chlorophyll fluorescence parameters was caused by drought stress. Severity of drought was proportional to adverse impacts on chlorophyll fluorescence. Drought stress lowered $\mathrm{F}_{0}(2.9 \%-6.9 \%), \mathrm{F}_{\mathrm{m}}(12.7 \%-19.0 \%)$, $\mathrm{F}_{\mathrm{v}} / \mathrm{F}_{\mathrm{m}}$ (3.7\%-4.9\%), qP (4.2\%-7.3\%), and $\Phi$ PSII (1.9\%-10.3\%), depending upon the stress severity. While qN was improved by 5.0\%-11.0\%, depending upon the stress severity. BR application improved the chlorophyll fluorescence under all conditions of stress. Brassinosteroid mediated improvements in $\mathrm{F}_{0}, \mathrm{~F}_{\mathrm{m}}, \mathrm{F}_{v} / \mathrm{F}_{\mathrm{m}}, \mathrm{qP}$, and $\Phi P S I I$. The $\mathrm{qN}$ was reduced by BR application at both moderate and severe stress by $9.6 \%$ and $1.0 \%$, respectively, over untreated control (Table 2 ).

\section{DISCUSSION}

Drought stress severely affects plant growth and development by imposing its adverse effects on normal functioning of photosynthetic efficiency, enzyme activity, and through oxidative stress by ROS (Farooq et al., 2009). However, plants tend to turn on the physiological and metabolic mechanisms that aid in the maintenance of tissue water status and avoid the injuries of oxidative burst (Ahmadi et al., 2010). In the present study, growth attributes of L. chinensis plants viz. plant fresh weight and relative water contents were reduced under water deficit (Figure 1). Aninbon et al. (2016) found that water deficit conditions lowered the relative water content in peanut plants. Similarly, Zhao et al. (2015) reported decrease in dry biomass production under drought. Nevertheless, in our study the BR treatment of L. chinensis plants improved all the growth attributes at each level of stress (Figure 1). The improvement in growth of L. chinensis plants by

Table 1. Effect of foliar application of brassinosteroid (BR) on gas exchange attributes of Leymus chinensis under varying levels of drought stress.

\begin{tabular}{|c|c|c|c|c|c|c|c|c|}
\hline Treatments & $P_{N}$ & $g_{s}$ & $\mathrm{C}_{\mathrm{i}}$ & $\mathrm{E}$ & WUE & CUE & $\mathrm{L}_{\mathrm{s}}$ & SUE \\
\hline & $\mu \mathrm{mol} \mathrm{m} \mathrm{m}^{-2} \mathrm{~s}^{-1}$ & $\begin{array}{c}\operatorname{mmol}\left(\mathrm{H}_{2} \mathrm{O}\right) \\
\mathrm{m}^{-2} \mathrm{~s}^{-1}\end{array}$ & $\begin{array}{c}\mu \mathrm{mol}\left(\mathrm{CO}_{2}\right) \\
\mathrm{mol}^{-1}\end{array}$ & $\begin{array}{c}\operatorname{mmol}\left(\mathrm{H}_{2} \mathrm{O}\right) \\
\mathrm{m}^{-2} \mathrm{~s}^{-1}\end{array}$ & $\begin{array}{c}\mu \mathrm{mol}\left(\mathrm{CO}_{2}\right) / \mathrm{mmol} \\
\qquad\left(\mathrm{H}_{2} \mathrm{O}\right)^{-1}\end{array}$ & $\mathrm{~mol} \mathrm{~m} \mathrm{~m}^{-2} \mathrm{~s}^{-1}$ & $-\%$ & \\
\hline $\mathrm{T} 0$ & $1.480 \pm 0.11 b$ & $0.048 \pm 0.006 b$ & $322.3 \pm 8.03 b c$ & $1.640 \pm 0.21 \mathrm{a}$ & $1.071 \pm 0.19 b$ & $0.0046 \pm 0.0004 b$ & $0.190 \pm 0.020 \mathrm{ab}$ & $0.150 \pm 0.010 \mathrm{~b}$ \\
\hline ТВ0 & $2.490 \pm 0.086 \mathrm{a}$ & $0.069 \pm 0.010 \mathrm{a}$ & $294.7 \pm 12.81 \mathrm{c}$ & $1.830 \pm 0.22 \mathrm{a}$ & $1.560 \pm 0.23 \mathrm{ab}$ & $0.0086 \pm 0.0006 \mathrm{a}$ & $0.260 \pm 0.032 \mathrm{a}$ & $0.250 \pm 0.00 \mathrm{a}$ \\
\hline $\mathrm{T} 1$ & $0.850 \pm 0.033 \mathrm{c}$ & $0.021 \pm 0.003 \mathrm{c}$ & $346.6 \pm 7.36 b$ & $0.645 \pm 0.056 b c$ & $1.460 \pm 0.203 \mathrm{ab}$ & $0.0025 \pm 0.0001 \mathrm{c}$ & $0.130 \pm 0.018 \mathrm{ab}$ & $0.085 \pm 0.003 \mathrm{c}$ \\
\hline TB1 & $1.450 \pm 0.068 b$ & $0.030 \pm 0.004 c$ & $316.7 \pm 8.72 b c$ & $0.935 \pm 0.11 b$ & $1.690 \pm 0.204 \mathrm{a}$ & $0.0045 \pm 0.0002 b$ & $0.210 \pm 0.022 \mathrm{ab}$ & $0.140 \pm 0.007 b$ \\
\hline $\mathrm{T} 2$ & $0.166 \pm 0.019 \mathrm{e}$ & $0.050 \pm 0.001 \mathrm{~d}$ & $410.8 \pm 30.15 a$ & $0.147 \pm 0.007 \mathrm{~d}$ & $1.140 \pm 0.14 \mathrm{ab}$ & $0.0004 \pm 0.0001 \mathrm{e}$ & $0.027 \pm 0.075 \mathrm{c}$ & $0.017 \pm 0.002 \mathrm{e}$ \\
\hline TB2 & $0.440 \pm 0.024 \mathrm{~d}$ & $0.014 \pm 0.003 \mathrm{~cd}$ & $324.3 \pm 14.09 \mathrm{bc}$ & $0.363 \pm 0.024 \mathrm{~cd}$ & $1.250 \pm 0.082 \mathrm{ab}$ & $0.0014 \pm 0.0001 \mathrm{~d}$ & $0.190 \pm 0.035 b$ & $0.044 \pm 0.002 \mathrm{~d}$ \\
\hline
\end{tabular}

Values in the table are means \pm SE $(n=5)$. Values followed by the same letter within columns are not significantly different according to Duncan's multiple range test $(P<0.05)$.

DAT: Days after treatments; T0: control; TB0: control + BR; T1: moderate drought stress; TB1: moderate drought stress + BR; T2: severe drought stress; TB2: severe drought stress+ BR.

$\mathrm{P}_{\mathrm{N}}$ : Net photosynthetic rate; $\mathrm{g}_{\mathrm{s}}$ : stomatal conductance; $\mathrm{C}_{\mathrm{i}}$ : intercellular $\mathrm{CO}_{2}$ concentration; E: transpiration rate; WUE: water utilization efficiency; WUE: $\mathrm{P}_{\mathrm{N}} / \mathrm{E}$; CUE: carboxylation utilization efficiency, $\mathrm{CUE}=\mathrm{P}_{\mathrm{N}} / \mathrm{C}_{\mathrm{i}} ; \mathrm{L}_{\mathrm{s}}$ : stomata limitation, $\mathrm{L}_{\mathrm{s}}=1-\mathrm{C}_{\mathrm{i}} / \mathrm{Ca}\left(\mathrm{Ca}\right.$ : atmosphere $\mathrm{CO} \mathrm{O}_{2}$ concentration); SUE: sunlight utilization efficiency, $\mathrm{SUE}=\mathrm{P}_{\mathrm{N}} / \mathrm{PAR}$; PAR: photosynthetic active radiation. 
Table 2. Effect of foliar application of brassinosteroid (BR) on chlorophyll fluorescence of Leymus chinensis under varying levels of drought stress.

\begin{tabular}{|c|c|c|c|c|c|c|}
\hline Treatments & $\mathrm{F}_{0}$ & $\mathrm{~F}_{\mathrm{m}}$ & $\mathrm{F}_{\mathrm{v}} / \mathrm{F}_{\mathrm{m}}$ & $\mathrm{qP}$ & $\mathrm{qN}$ & ФPSII \\
\hline T0 & $32.67 \pm 1.14 \mathrm{a}$ & $155.55 \pm 5.96 \mathrm{ab}$ & $0.78 \pm 0.003 b$ & $0.74 \pm 0.014 \mathrm{a}$ & $2.36 \pm 0.13 a$ & $0.43 \pm 0.023 a$ \\
\hline TB0 & $32.56 \pm 1.66 \mathrm{a}$ & $162.46 \pm 8.57 \mathrm{a}$ & $0.81 \pm 0.005 \mathrm{a}$ & $0.75 \pm 0.016 \mathrm{a}$ & $2.19 \pm 0.090 \mathrm{a}$ & $0.45 \pm 0.016 \mathrm{a}$ \\
\hline $\mathrm{T} 1$ & $31.71 \pm 1.37 \mathrm{a}$ & $135.79 \pm 6.01 \mathrm{~cd}$ & $0.75 \pm 0.001 \mathrm{e}$ & $0.71 \pm 0.028 \mathrm{a}$ & $2.48 \pm 0.12 \mathrm{a}$ & $0.42 \pm 0.021 \mathrm{a}$ \\
\hline TB1 & $32.88 \pm 1.13 \mathrm{a}$ & $148.45 \pm 4.70 \mathrm{abc}$ & $0.77 \pm 0.002 \mathrm{c}$ & $0.72 \pm 0.012 \mathrm{a}$ & $2.24 \pm 0.20 \mathrm{a}$ & $0.44 \pm 0.0152 \mathrm{a}$ \\
\hline $\mathrm{T} 2$ & $30.41 \pm 0.48 \mathrm{a}$ & $126.04 \pm 1.96 \mathrm{~d}$ & $0.74 \pm 0.001 \mathrm{f}$ & $0.69 \pm 0.026 \mathrm{a}$ & $2.62 \pm 0.11 \mathrm{a}$ & $0.38 \pm 0.027 \mathrm{a}$ \\
\hline TB2 & $32.44 \pm 0.63 a$ & $140.82 \pm 1.13 \mathrm{bcd}$ & $0.76 \pm 0.002 \mathrm{~d}$ & $0.71 \pm 0.025 \mathrm{a}$ & $2.59 \pm 0.13 a$ & $0.39 \pm 0.036 a$ \\
\hline
\end{tabular}

Values in the table are means \pm SE $(n=5)$. Values followed by the same letter within columns are not significantly different according to Duncan's multiple range test $(P<0.05)$.

DAT: Days after treatments; T0: control; TB0: control + BR; T1: moderate drought stress; TB1: moderate drought stress + BR; T2: severe drought stress; TB2: severe drought stress+ BR.

$\mathrm{F}_{0}$ : Minimal fluorescence; $\mathrm{F}_{\mathrm{m}}$ : maximal fluorescence; $\mathrm{F}_{\mathrm{v}}=\mathrm{F}_{\mathrm{m}}-\mathrm{F}_{0}$, variable fluorescence; PSII $\left(\mathrm{F}_{\mathrm{v}} / \mathrm{F}_{\mathrm{m}}\right)$ : optimal photochemical efficiency of photosystem II in the dark; qP: photochemical quenching coefficient; qN: non-photochemical quenching coefficient; ФPSII: effective quantum yield of PSII.

BR application under drought stress are attributable to positive alterations in cell division and elongation, and improved photosynthetic activity (Vriet et al., 2012). Earlier report of Nassar (2004) supports our results, who noticed an increase in plant height, and fresh weight of banana plant by application of homobrassinolide when heat stress was applied.

Abiotic stresses aggravate the production of ROS and trigger lipid peroxidation of biological membranes, resulting in accumulation of MDA and rendering the membranes leaky (Anjum et al., 2012). Therefore, higher levels of MDA and EC of L. chinensis plants under drought stress were aggravated from moderate to severe stress. However, treatment with BR decreased the accumulation of MDA as well as EC at each level of drought stress (Figure 2). The mentioned findings are in accord with Ogweno et al. (2008) who noticed elevated accumulation of MDA content in tomato under heat stress; while, application of 24-epibrassinolide significantly reduced MDA contents.

Under drought and other stress conditions, plants accumulate large amounts of various osmo-protectants such as glycine betaine, proline, soluble sugars, and free amino acids that ultimately maintained the tissue water status and protect the cellular organelles as well as organic molecules from ROS by acting as physical barrier (Farooq et al., 2009; Kumar et al., 2012; Zong et al., 2018). Increased accumulation of osmo-protectants under drought stress might have aggravated stress severity. Moreover, BR treatment further enhanced their accumulation at each level of stress (Figure 3). In an earlier study Jin-huan et al. (2015) observed that application of brassinolide improved the accumulation of osmo-protectants such as soluble sugars and proteins in L. chinensis plants in response to salt stress, which was negatively correlated with MDA and enhanced photosynthetic pigments and plant growth over control.

Plant growth is essentially dependent on photosynthetic activity. Abiotic stresses mostly impact photosynthetic efficiency either by disrupting the photosynthetic machinery or by perturbation of stomatal activity (Ghobadi et al., 2013). Drought stress declined the photosynthetic pigments and gas exchange characters of L. chinensis plant and the deleterious effects were proportional to increased stress severity (Figure 4, Tables 1). Drought stress aggravated the production of ROS that eventually caused oxidative damage to cellular organelles, biological membranes, and organic molecules such as chlorophyll (Anjum et al., 2011; Silva et al., 2015). Sun et al. (2013) observed that drought stress depicted damaging effects on photosynthetic pigments and gas exchange characters of chrysanthemum and there was a reduction in chlorophyll contents. Drought also lowered $\mathrm{P}_{\mathrm{N}}, \mathrm{E}$, and $\mathrm{g}_{\mathrm{s}}$. Furthermore, exaggeration in injuries to photosynthetic pigments and gas exchange attributes was noticed by increasing stress severity. In present study, the application of BR was helpful in improving the photosynthetic pigments as well as gas exchange characters (Figure 4, Table 1). This might be due to better maintenance of tissue water status and photosynthetic machinery protection due to enhanced accumulation of osmo-protectants when L. chinensis was treated with BR. Earlier report of Hayat et al. (2010) is in accord with ours that temperature and salt stress substantially reduced the chlorophyll content and negatively affected the gas exchange characteristics such as $\mathrm{P}_{\mathrm{N}}, \mathrm{g}_{\mathrm{s}}, \mathrm{C}_{\mathrm{i}}$, WUE, and $\mathrm{E}$ of Vigna radiata, nonetheless, 28-homobrassinolide application improved the chlorophyll content as well as gas exchange characteristics.

Harm caused by ROS to photosynthetic machinery eventually led to decrease in photosynthetic efficiency of chlorophyll (Huang et al., 2013). Similar results were obtained in the present study where drought stress declined the photosynthetic efficiency and quantum yield of PSII in L.chinensis and the increasing stress severity extoled the injurious effects on PSII 
Figure 4. Effect of foliar application of brassinosteroid (BR) on photosynthetic pigments of Leymus chinensis under varying levels of drought stress.
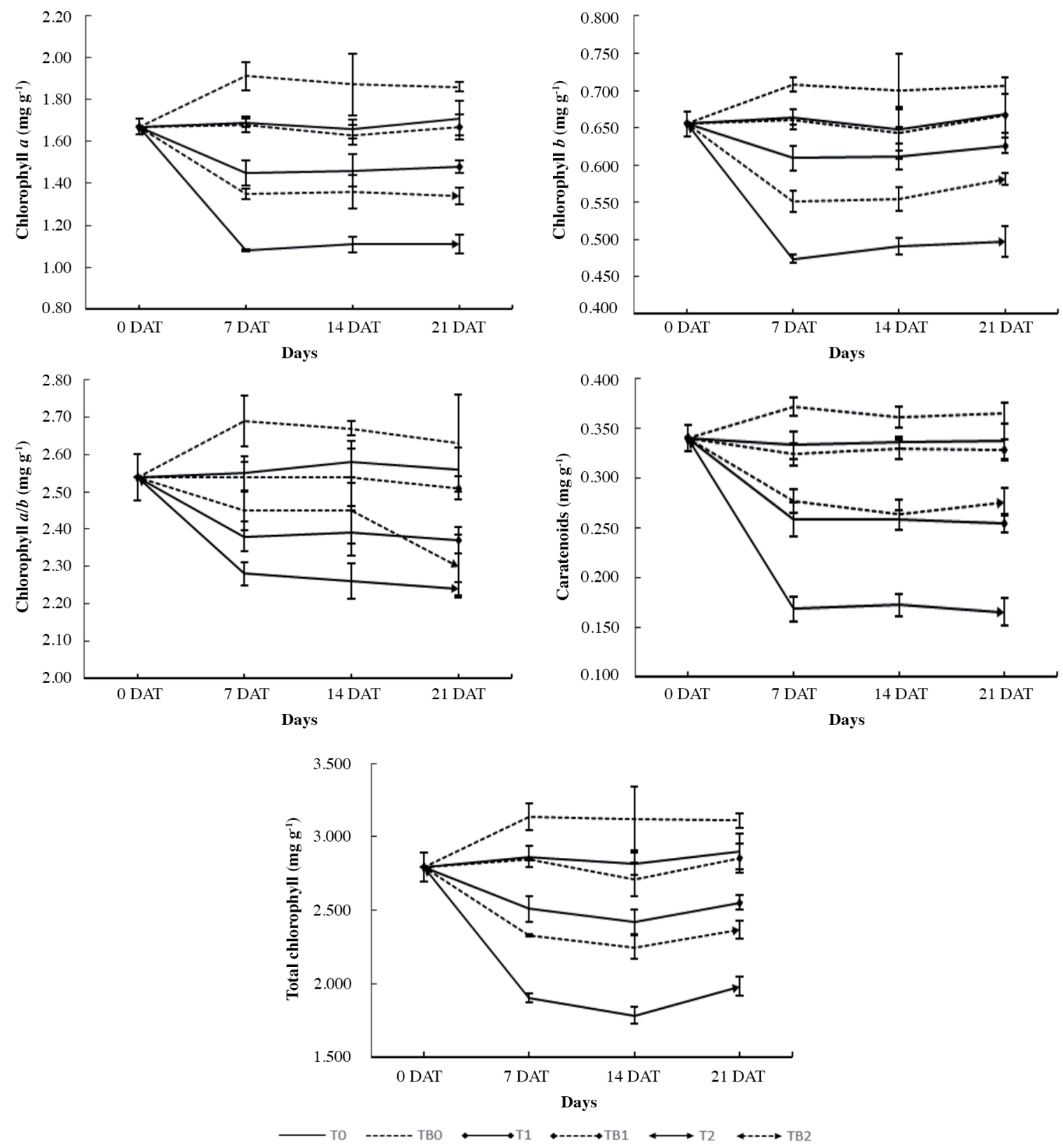

Mean value \pm SE $(n=5)$. DAT: Days after treatments; T0: control; TB0: control + BR; T1: moderate drought stress; TB1: moderate drought stress + BR; T2: severe drought stress; TB2: severe drought stress+ BR.

(Table 2). Rakic et al. (2015) reported a decline in $\mathrm{F}_{0}$ and $\mathrm{F}_{\mathrm{m}}$ of Chla, $\mathrm{qP}$, and ETR of Ramonda serbica and $R$. nathaliae in response to drought stress. Decrease in chlorophyll fluorescence by drought might be a consequence of complete dehydration with the aggravating severity of drought. However, the application of BR to L. chinensis plants boosted the chlorophyll fluorescence over control and alleviated adverse impacts of drought (Table 2). Improvement in $F_{v} / F_{m}$ by the application of BR can be ascribed to BR modulated assistance in the protection of PSII from loss of integrity of thylakoid membrane. Brassinosteroid application triggered the detoxification of ROS under drought and thus improved $\mathrm{F}_{\mathrm{v}} / \mathrm{F}_{\mathrm{m}}$. Increments in $\mathrm{F}_{\mathrm{v}} / \mathrm{F}_{\mathrm{m}}$ under exogenous $\mathrm{BR}$ might also be a consequence of decreased sensitivity of thylakoid membranes 
to abiotic stresses (Haldimann and Feller, 2005). The reports from earlier studies have revealed that BR application improved quantum yield in Lycopersicon esculentum under high temperature stress (Ogweno et al., 2008) and in wheat under salt stress (Shahbaz et al., 2008).

\section{CONCLUSIONS}

Drought stress declined the growth, development, and biomass accumulation of Leymus chinensis plants by reducing the photosynthetic rate while aggravating the lipid peroxidation. Furthermore, adverse impacts of drought were proportional to the severity of drought stress. Brassinosteroid (BR) spray improved the growth, photosynthetic pigments, osmoprotectant accumulation, gas exchange attributes, and chlorophyll fluorescence while lowering the malondialdehyde contents. BR application improves the stress tolerance of $L$. chinensis plants, even at severe drought stress, by improving osmo-protectants, relative water contents, net photosynthetic rate, photosynthetic pigments, stomatal conductance, water use efficiency, transpiration, solar radiation use efficiency, carboxylation efficiency, and chlorophyll maximal and minimal fluorescence and thus can prove an effective tool to alleviate adverse impacts of drought on L. chinensis.

\section{ACKNOWLEDGEMENTS}

The authors are grateful to National Key Basic Research Program of China (2014CB138806) along with Crop Germplasm Resources Utilization and Innovation Base Program of the 111 Project of China (104510-205001).

\section{REFERENCES}

Ahmadi, A., Emam, Y., and Pessarakli, M. 2010. Biochemical changes in maize seedlings exposed to drought stress conditions at different nitrogen levels. Journal of Plant Nutrition 33:541-556.

Aninbon, C., Jogloy, S., Vorasoot, N., Patanothai, A., Nuchadomrong, S., and Senawong, T. 2016. Effect of end of season water deficit on phenolic compounds in peanut genotypes with different levels of resistance to drought. Food Chemistry 196:123L.1-129.

Anjum, S.A., Ehsanullah, L., Xue, L., Wang, L., Saleem, M.F., and Huang, C. 2013. Exogenous benzoic acid (BZA) treatment can induce drought tolerance in soybean plants by improving gas-exchange and chlorophyll contents. Australian Journal of Crop Science 7:555-560.

Anjum, S.A., Farooq, M., Xie, X., Liu, X., and Ijaz, M.F. 2012. Antioxidant defense system and proline accumulation enables hot pepper to perform better under drought. Scientia Horticulturae140:66-73.

Anjum, S.A., Wang, L., Farooq, M., Khan, I., and Xue, L. 2011. Methyl jasmonate-induced alteration in lipid peroxidation, antioxidative defence system and yield in soybean under drought. Journal of Agronomy and Crop Science 197:296-301 .

Divi, U.K., Rahman, T., and Krishn, P. 2010. Brassinosteroid-mediated stress tolerance in Arabidopsis shows interactions with abscisic acid, ethylene and salicylic acid pathways. BMC Plant Biology 10:151.

Farooq, M., Wahid, A., Kobayashi, N., Fujita, D., and Basra, S.M.A. 2009. Plant drought stress: effects, mechanisms and management. Agronomy for Sustainable Development 29:185-212.

Gao, H., Zong, X., Lu, J., Xu, Y., He, X., Dong, Y., et al. 2018. Photosynthetic physiology changes of rice in combined high temperature and drought stress at grain-filling stage. Ecology and Environmental Monitoring of Three Gorges 3(2):68-76.

Ghobadi, M., Taherabadi, S., Ghobadi, M.E., Mohammadi, G.R., and Jalali-Honarmand, S. 2013. Antioxidant capacity, photosynthetic characteristics and water relations of sunflower (Helianthus annuus L.) cultivars in response to drought stress. Industrial Crops and Products 50:29-38.

Haldimann, P., and Feller, U. 2005. Growth at moderately elevated temperature alters the physiological response of the photosynthetic apparatus to heat stress in pea (Pisum sativum L.) leaves. Plant Cell and Environment 28:302-317.

Hayat, S., Hasan, S.A., Yusuf, M., Hayat, Q., and Ahmad, A. 2010. Effect of 28-homobrassinolide on photosynthesis, fluorescence and antioxidant system in the presence or absence of salinity and temperature in Vigna radiata. Environmental and Experimental Botany 69:105-112.

Huang, C.J., Wei, G., Jie, Y.C., Xu, J.J., Zhao, S.Y., Wang, L.C., et al. 2015. Responses of gas exchange, chlorophyll synthesis and ROS-scavenging systems to salinity stress in two ramie (Boehmeria nivea L.) cultivars. Photosynthetica 53:455-463.

Huang, S., Wu, Y.N., and Liu, M. 2010. Quantitative determination of total free-amino acid in Nervilia fordii (Hance) Schltr. by ninhydrin colorimetric method. Chinese Journal of Information on TCM 12:50-52. 
Huang, C., Zhao, S., Wang, L., Anjum, S.A., Chen, M., Zhou, H., et al. 2013. Alteration in chlorophyll fluorescence, lipid peroxidation and antioxidant enzymes activities in hybrid ramie (Boehmeria nivea L.) under drought stress. Australian Journal of Crop Science 7:594-599.

Kumar, S., Gupta, D., and Nayyar, H. 2012. Comparative response of maize and rice genotypes to heat stress: Status of oxidative stress and antioxidants. Acta Physiologiae Plantarum 34:75-86.

Jin-huan, L., Anjum, S.A., Mei-ru, L., Jian-hang, N., Ran, W., Ji-xuan, S., et al. 2015. Modulation of morpho-physiological traits of Leymus chinensis (Trin.) through exogenous application of brassinolide under salt stress. Journal of Animal and Plant Sciences 25:1055-1062.

Liu, M., Anjum, S.A., Li, J., Niu, J., Wang, R., Song, J., et al. 2015. Exogenous application of brassinolide ameliorates mowing stress in Leymus chinensis (Trin.) Philippine Agricultural Scientist 98:202-208.

Liu, G.S., Li, X.X., Qi, D.M., Chen, S.L., and Cheng, L.Q. 2016. Evaluation and utilization of Leymus chinensis germplasm resources. Chinese Science Bulletin 61:271-281.

Nassar A.H. 2004. Effect of homobrassinolide on in vitro growth of apical meristems and heat tolerance of banana shoots. International Journal of Agriculture and Biology 6:771-776.

Ogweno, J.O., Song, X.S., Shi, K., Hu, W.H., Mao, W.H., Zhou, Y.H., et al. 2008. Brassinosteroids alleviate heat induced inhibition of photosynthesis by increasing carboxylation efficiency and enhancing antioxidant systems in Lycopersicon esculentum. Journal of Plant Growth Regulation 27:49-57.

Rakic, T., Gajic, G., Lazarevic, M., and Stevanovic, B. 2015. Effects of different light intensities, $\mathrm{CO}_{2}$ concentrations, temperatures and drought stress on photosynthetic activity in two paleoendemic resurrection plant species Ramonda serbica and R. nathaliae. Environmental and Experimental Botany 109:63-72.

Sapeta, H., Costa, J.M., Lourenco, T., Marocod, J., van der Linde, P., and Oliveira M.M. 2013. Drought stress response in Jatropha curcas: Growth and physiology. Environmental and Experimental Botany 85:76-84.

Shahbaz, M., Ashraf, M., and Athar, H.R. 2008. Does exogenous application of 24-epibrassinolide ameliorate salt induced growth inhibition in wheat (Triticum aestivum L.) Plant Growth Regulation 55:51-64.

Silva, E.N., Silveira, J.A.G., Ribeiro, R.V., and Vieira, S.A. 2015. Photoprotective function of energy dissipation by thermal processes and photorespiratory mechanisms in Jatropha curcas plants during different intensities of drought and after recovery. Environmental and Experimental Botany 110:36-45.

Sun, J., Gu, J., Zeng, J., Han, S., Song, A., Chen, F., et al. 2013. Changes in leaf morphology, antioxidant activity and photosynthesis capacity in two different drought-tolerant cultivars of chrysanthemum during and after water stress. Scientia Horticulturae 161:249-258.

Vriet, C., Russinova, E., and Reuzeau, C. 2012. Boosting crop yields with plant steroids. Plant Cell 24:842-857.

Zhao, R., Guo, W., Bi, N., Guo, J., Wang, L., Zhao, J., and Zhang, J. 2015. Arbuscular mycorrhizal fungi affect the growth, nutrient uptake and water status of maize (Zea mays L.) grown in two types of coal mine spoils under drought stress. Applied Soil Ecology 88:41-49.

Zong, X., Yang, A., Anjum, S.A., Lv, J., Li, N., He, X., et al. 2018. Effects of brassinolide application on antioxidant characteristic and endogenous hormones of Leymus chinensis (Trin.) Tzvelev under different light intensity regimes. Chilean Journal of Agricultural Research 78:539-548. 